\title{
intuitio
}

\section{A CONTROVÉRSIA SOBRE AS FORÇAS VIVAS E A PRIMEIRA OBRA DE KANT: NA FRONTEIRA ENTRE METAFÍSICA E CIÊNCIA}

\author{
THE VIS VIVA CONTROVERSY AND THE FIRST WORK OF KANT: \\ IN THE BORDER BETWEEN METAPHYSICS AND SCIENCE
}

Elton Cândido Ribeiro'

Resumo: O presente artigo se propõe a oferecer uma abordagem introdutória da primeira obra de Immanuel Kant, os Pensamentos sobre a verdadeira estimação das forças vivas, publicada em 1749. Num primeiro momento, procura-se compreender as possíveis motivações de Kant ao publicar este trabalho em língua vernácula - mesmo em meio a dificuldades financeiras - a partir do ambiente da Universidade de Königsberg. Em seguida, alude-se brevemente ao contexto histórico-filosófico da controvérsia sobre as forças vivas que, basicamente, consistia numa diferença entre cartesianos e leibnizianos a respeito da mensuração da força de um corpo em movimento. Por fim, apresenta-se a posição de Kant no debate, tal como se encontra na referida obra, avaliando-a em seus aspectos científico, metafísico e metodológico. A tese central consiste em afirmar que, ainda que o primeiro escrito de Kant apresente lacunas no tocante ao conhecimento científico de seu tempo, oferece aportes interessantes para a compreensão do desenvolvimento filosófico do autor.

Palavras-chave: Kant. Metafísica. Física. Forças Vivas.

\footnotetext{
1 Pontifícia Universidade Católica de São Paulo (PUCSP). ORCID: http://orcid.org/oooo-00025637-367X. E-Mail: elton_mail@yahoo.com.br
} 


\begin{abstract}
The present paper aims to offer an introductory approach of Immanuel Kant's first work, namely, the Thoughts on the true estimation of living forces, published in 1749. In a first moment, it tries to understand Kant's possible motivations when publishing this work in vernacular language (even in middle of financial difficulties), from the ambience of the University of Königsberg. Next, it refers briefly to the historical-philosophical context of the controversy about living forces, which basically consisted of a difference between Cartesians and Leibnizians regarding the measurement of the force of a moving body. Finally, it presents Kant's position in the debate, as it is presented in the mentioned work, evaluating it in its scientific, metaphysical and methodological aspects. The central thesis is that, although Kant's first work presents gaps with regard the scientific knowledge of his time, he offers interesting contributions to the understanding of the author's philosophical development.
\end{abstract}

Keywords: Kant. Metaphysics. Physics. Living Forces.

Em 1746, quando contava com apenas 22 anos, Kant escreveu seu primeiro trabalho, os Pensamentos sobre a verdadeira estimação das forças vivas $^{2}$, que marcou o desfecho de seus anos de estudante na universidade. Dadas as dificuldades surgidas com a morte do pai naquele mesmo ano, Kant só conseguiria publicá-lo em 1749, não sem ajuda financeira de outrem. Não há qualquer informação biográfica que dê a conhecer os motivos intelectuais que levaram o jovem Kant a se ocupar com esta questão. Sabe-se, de modo vago, que ele frequentara, desde o início de seus estudos na Albertina, as aulas de filosofia e de ciência de Martin Knutzen. Grande conhecedor das ciências de seu tempo, este teria exercido especial influência sobre Kant

\footnotetext{
2 O título original e completo é: Gedanken von der wahren Schätzung der lebendigen Kräfte und Beurteilung der Beweise, deren sich Herr von Leibniz und andere Mechaniker in dieser Streitsache bedient haben, nebst einigen vorhergehenden Betrachtungen, welche die Kraft der Körper überhaupt betreffen [Pensamentos sobre a verdadeira estimação das forças vivas e avaliação das provas das quais o Senhor de Leibniz e outros estudiosos da mecânica se serviram nesta questão disputada, junto com algumas observações prévias relacionadas à força dos corpos em geral]. As obras completas de Kant foram publicadas progressivamente ao longo do século XX, inicialmente pela Academia Real Prussiana de Ciências e, depois, pela Academia de Ciências de Berlim. Esta e outras obras de Kant serão citadas segundo a Edição da Academia, da seguinte maneira: Ak I, 1-10. A sigla Ak indica que a obra é citada segundo a edição da Academia; o algarismo romano, o respectivo tomo naquela edição; os algarismos arábicos, a paginação.
} 
no que diz respeito a seu interesse pelas ciências da natureza ${ }^{3}$. É ainda mais misterioso o fato de que tenha publicado seu trabalho em alemão, e não em latim, a língua acadêmica, o que naturalmente se esperaria de alguém que pretendesse seguir carreira como professor, seja no colégio ou na universidade, submetendo, para tanto, seu trabalho à avaliação dos professores e, assim, obter o título de Magister ${ }^{4}$.

Mesmo que Kant tenha publicado sua obra em língua vernácula, permitindo que um público maior do que aquele do círculo universitário pudesse tomar contato com seu trabalho, ela não foi, em absoluto, um sucesso editorial. Na verdade, do ponto de vista estritamente científico, a obra se revela insuficiente, quando comparada, por exemplo, ao trabalho de Euler, Mechanica sive motus scientia, publicado já em 1736. O autor demonstra não estar plenamente familiarizado ao conteúdo mais fundamental da educação matemática de seu tempo - ignora, por exemplo, o recente Traité de Dynamique, de d'Alembert, publicado três anos antes e considerado por muitos como a obra que dirimiu, em definitivo, a polêmica das forças vivas 5 . Ademais, as distinções utilizadas, como "forças vivas" e "mortas", "pressão morta" e "movimento efetivo", foram derrubadas pela mecânica moderna, em sua exigência de definições precisas dos conceitos básicos e de mensurar com exatidão todas as relações em jogo ${ }^{6}$. O clássico e cáustico epigrama de Lessing, segundo o qual Kant ter-se-ia

3 Cf. BOROWSKI, Ludwig Ernst. "Darstellung des Lebens und Charakters Immanuel Kants". In: SCHWARZ, Hermann. Immanuel Kant: ein Lebensbild nach Darstellungen der Zeitgenossen. Halle: Hugo Peter, 1907, p. 7ss. Borowski destaca também a influência do professor de física, Teske. A escolha do tema das forças vivas, no entendimento de Borowski, é prova inequívoca da influência de ambos.

4 Cf. KUEHN, Manfred. Kant: A Biography. Cambridge: Cambridge University Press, 2002, p. 87.

5 Os biógrafos contemporâneos, via de regra, parecem considerar o desconhecimento do tratado de d'Alembert como uma pecha considerável da obra de Kant. Otfried Höffe, em conhecida biografia, alega que Kant, nesta obra "ainda não acertou o alvo" e que "a solução verdadeira $\left(F=1 / 2 m v^{2}\right.$ ), publicada por d'Alembert em 1743, permanece desconsiderada" (HÖFFE, Otfried. Imanuel Kant. São Paulo: Martins Fontes, 2005, p. 7). O papel de d'Alembert na polêmica será brevemente discutido no tópico seguinte.

6 Cf. CASSIRER, Ernst. Kants Leben und Lehre. Berlin: Bruno Cassirer, 1921, p. $28 \mathrm{ss}$. 
proposto a medir as forças vivas, porém, esquecendo-se de mensurar as suas próprias, parece mostrar-se verdadeiro7.

Por esses motivos, a obra passou despercebida não só para os contemporâneos de Kant, mas também para a posteridade, ocupando uma posição de marginalização em relação aos demais escritos kantianos ${ }^{8}$. Ela não seria mais do que um pecado de juventude, expressão de uma ingenuidade juvenil que acredita poder açambarcar a tudo e oferecer para os mais variados problemas soluções marcadas de ineditismo. Seria esse, porém, o caso? Que motivos teriam levado o jovem Kant, para além de uma pretensa e vaga influência de Knutzen sobre ele, a escrever os Pensamentos? O que representaria, exatamente, a ausência de menção ao tratado de d'Alembert?

\section{O CAMINHO QUE O JOVEM KANT TRAÇOU PARA SI}

Poderia ocorrer, todavia, que o ataque, anunciado no "Prefácio" dos Pensamentos não se dirigisse apenas "aos grandes mestres do conhecimento humano" (Ak I, 10), Leibniz, Descartes e Newton, e que a afirmação de seu "caminho"9 não se endereçasse ao público alemão em geral, mas também à comunidade acadêmica de Königsberg, em particular. De modo ainda mais preciso, quer-se afirmar que, muito embora Kant seja

\footnotetext{
7 "K* unternimmt ein schwer Geschäfte, / Der Welt zum Unterricht. / Er schätzet die lebendigen Kräfte, / Nur seine schätzt er nicht" (LESSING, G. E. "In dem Neuesten aus dem Reichen des Witzes". In: LESSING, G. E. Sämtliche Schriften. Vol. 13. Berlin: Voß'sche Buchhandlung, 1840, p. 640). "Kant empreendeu uma difícil tarefa, para ensinar ao mundo. Ele estimou as forças vivas, somente não estima as suas" (em alemão antigo).

8 "De todos los escritos kantianos, ha sido el menos editado y traducido, el menos recensionado y comentado, el menos alabado y, sorprendentemente, también uno de los menos criticados. En efecto: aunque no han faltado plumas bien dispuestas que se han empleado a fondo en disimular los aspectos más dudosos del trabajo y ensalzar los escasos pasajes donde es posible atisbar algo del futuro destello del autor, los enemigos de la filosofía crítica en cambio apenas parecen haberse dado cuenta de la existencia de un blanco tan vulnerable entre las producciones de su creador" (CAÑEDO-ARGÜELLES, Juan Arana. Pensamientos sobre la verdadera estimación de las fuerzas vivas. Berna: Peter Lang, 1988, p. 200).

9 "Eu já tracei para mim o caminho que eu devo tomar. Eu seguirei o meu curso e nada deve me impedir de continuar" (Ak I, 10).
} 
retratado, em seus anos na universidade, como uma espécie de protégé de Martin Knutzen, há razões, ao menos, para se relativizar essa alegação'

De fato, Knutzen não parece ter tido Kant em tão alta conta entre seus estudantes. Em primeiro lugar, Kant não é sequer mencionado pelos primeiros biógrafos de Knutzen como um de seus alunos. Além disso, há evidências que apontam Friedrich Johann Buck (1722-86) como um de seus favoritos: apenas um pouco mais velho que Kant, fez, ao menos uma vez, as repetitoria (revisões de aula) para Knutzen; foi ele, ainda, quem levou adiante as aulas de Knutzen após sua morte em 1751 e também deu prosseguimento às suas correspondências científicas. Outro estudante valorizado por ele foi Johann Friedrich Weitenkampf (1726-1758): Knutzen oportunizou a ele a leitura de um discurso em 1744, no bicentenário da Universidade de Königsberg, sobre a utilidade da academia para o bem-estar das nações e, depois, cuidou para que este fosse publicado. Ademais, o nome de Kant não é mencionado por Knutzen entre os estudantes excepcionais que lista na sua correspondência com Euler"11.

Os Pensamentos, assim, podem ser mais uma reação a Knutzen, ainda que velada, do que uma obra positivamente influenciada por ele. $\mathrm{O}$ escrito, neste sentido, parece se afastar do meio intelectual em que se insere o velho professor, sobretudo por apresentar um tratamento da

10 Cf. KUEHN, Manfred. Kant: A Biography. Cambridge: Cambridge University Press, 2002, p. 88. Borowski, o biógrafo mais antigo de Kant, afirma, por exemplo: “Knutzen, um sábio juiz de mentes, encontrou nele [Kant] excelentes disposições, encorajava-o em conversas particulares, emprestava-Ihe em seguida especialmente as obras de Newton e, visto que isto agradava a Kant, o que mais ele desejasse de sua esplêndida e rica biblioteca" (BOROWSKI, Ludwig Ernst. "Darstellung des Lebens und Charakters Immanuel Kants”. In: SCHWARZ, Hermann. Immanuel Kant: ein Lebensbild nach Darstellungen der Zeitgenossen. Halle: Hugo Peter, 1907, p. 73). Uma vez que a biografia de Borowski foi revisada pelo próprio Kant, Kuehn aponta, curiosamente, que o biógrafo fez afirmações deste jaez "em passagens que o próprio Kant não viu, e nas passagens que Kant efetivamente viu, diz apenas que Kant frequentou as aulas de Knutzen e que ele era o professor de que Kant mais gostava" (KUEHN, Manfred. Kant: A Biography. Cambridge: Cambridge University Press, 2002, p. 88).

$"$ Cf. KUEHN, Manfred. Kant: A Biography. Cambridge: Cambridge University Press, 2002, pp. 88-89. 
questão que é mais especulativo do que matemático. Demonstra, de fato, independência em relação àquele meio em que se encontrava ${ }^{12}$.

Por sua vez, o desconhecimento do Traité de dynamique, de d'Alembert, não pode ser tomado como uma espécie de pecado original. Em primeiro lugar, há que se considerar que o isolamento geográfico de Königsberg impedia mesmo os professores de terem pronto acesso aos livros que circulavam no ambiente intelectual europeu. J. G. Bock (16981762), por exemplo, professor de poesia e retórica em Königsberg, escreve, em 1736, a Johann Christoph Gottsched (1700-66), filósofo wolffiano e crítico literário: "Como é sabido, eu vivo aqui em um lugar onde livros e escritos estrangeiros, não diferentemente dos cometas, são vistos por nós apenas depois de muitos anos"13. Naturalmente, um tratado escrito pouco tempo antes - ainda mais quando se considera que a redação de Pensamentos tenha começado, possivelmente, já em 1744 - não estaria em mãos de um professor de Königsberg e muito menos de um estudante. Há, todavia, uma outra razão. É somente a partir de inícios do século XIX que o nome de Jean d'Alembert aparece ligado à controvérsia da vis viva, como o responsável pela sua solução. Esta é, por assim dizer, uma solução semântica: a controvérsia consistiria muito mais numa disputa

12 Cf. KUEHN, Manfred. Kant: A Biography. Cambridge: Cambridge University Press, 2002, pp. 89-90. Naturalmente, Martin Knutzen é uma grande influência já neste primeiro trabalho de Kant e, como observa Mariano Campo, foi certamente o responsável por introduzir o estudante à polêmica, a qual lhe foi apresentada provavelmente na perspectiva que mais interessava a Knutzen, a saber, dentro do problema geral do commercium mentis et corporis (cf. CAMPO, Mariano. "Osservazioni sul primo lavoro precritico di Kant. Sulla misura delle forze vive". In: Rivista de filosofia neo-scolastica, Milano, v. 35, pp. 265-295, set./dez. 1943, pp. 266-267). Mas nem mesmo biógrafos antigos negariam que Kant se posicionasse diante desta influência desde cedo com espírito crítico e autonomia: "Kant aparece aqui [nos Pensamentos] como um decidido adepto daquela livre tendência do wolffianismo, da qual se contava Knutzen entre os representantes mais significativos. Que ele seja dominado, em toda parte nos pontos essenciais, pelo espírito da doutrina leibnizo-wolffiana, depreende-se claramente de cada parágrafo de seu escrito. Da mesma forma, porém, mostra-se clara e suficientemente, com frequência, que ele não interpreta aquele espírito segundo a letra da doutrina" (ERDMANN, Benno. Martin Knutzen und seine Zeit. Ein Beitrag zur Geschichte der Wolfischen Schule und insbesondere zur Entwicklungsgeschichte Kants. Leipzig: Verlag von Leopold Voss, 1876, p. 143).

13 Cf. ERDMANN, Benno. Martin Knutzen und seine Zeit: ein Beitrag zur Geschichte der wolffischen Schule und insbesondere zur Entwicklungsgeschichte Kants. Leipzig: Leopold Voss, 1876, p. 7. 
de palavras e não seria possível decidir-se empiricamente por $m v$ (a quantidade de movimento dos cartesianos) ou $\mathrm{mv}^{2}$ (as forças vivas dos leibnizianos). De qualquer modo, o que se quer questionar aqui é o papel histórico de d'Alembert no fim do debate. Para que se aceite o papel que lhe é atribuído, é preciso verificar, primeiro, (i) se a controvérsia em torno às forças vivas efetivamente se encerrou após 1743; (ii) caso tenha se encerrado, se os autores acreditavam no seu desfecho pelas mesmas razões de d'Alembert; (iii) finalmente, se os autores chegaram a esta conclusão pela leitura do tratado de d'Alembert. Ora, a história da controvérsia no século XVIII parece não satisfazer a nenhuma destas três condições. Com efeito, em primeiro lugar, não apenas Kant escreveu sobre a polêmica após 1743, mas inúmeros outros continuaram escrevendo sobre ela, revelando-a como uma disputa ainda acirrada e não resolvida: Daniel Bernoulli, em 1749; Roger Boscovich, em 1745 e, novamente, em 1758; Leonard Euler em 1745; tempos depois, Abbé Nollet, em suas Leçons de physique expérimentale ainda dedicará várias páginas a uma discussão acerca da controvérsia, expressando toda a sua vivacidade. Entre os ingleses a disputa também continuou encontrando diversas abordagens e possíveis soluções. Em segundo lugar, não se pode negar, por outro lado, que nos anos 1755-60 a controvérsia pareceu a vários proeminentes filósofos naturais como uma questão resolvida. Tal convicção, porém, não se originou da solução de d'Alembert, mas da certeza de que o momentum (quantidade de movimento cartesiana) se mostrou como a verdadeira medida de força - e este é o caso até mesmo de Boscovich, em 1758, ao lado de muitos outros. Assim, o aparente silêncio que pareceu imperar entre os notáveis da física acerca desta controvérsia nos anos de 1760, poderia levar a uma conclusão falaciosa a respeito da solução de d'Alembert: post hoc ergo propter hoc. Por fim, mesmo a alegada leitura original de d'Alembert acerca da controvérsia como semântica, ou seja, como um mal-entendido terminológico, era comum a outros estudiosos da mecânica que, porém, chegaram a ela não por sua influência, mas por caminhos independentes, como L'Abelye, Desaguliers e Reid. Nem mesmo 
na resenha do Traité de dynamique no Histoire de l'Académie Royale des Sciences o trabalho aparece como trazendo uma contribuição inovadora ou importante para a controvérsia. A única discussão entre 1743 e 1790 que confere um papel proeminente a d'Alembert na controvérsia é o verbete "força" da Encyclopédie, que, naturalmente, o próprio d'Alembert escreveu'14. Assim, é um juízo apressado considerar de antemão qualquer escrito sobre as forças vivas após 1743, que não faça eco às palavras de d'Alembert, como historicamente irrelevante e cientificamente ingênuo.

\section{A CONTROVÉRSIA SOBRE A VIS VIVA}

A polêmica das forças vivas lança suas raízes nos Principia philosophiae, de René Descartes, publicados em 1644. Na segunda parte da obra, no $\$ 43$, Descartes afirma o seguinte com relação à força dos corpos em movimento:

Assim, quando [o corpo] está em repouso tem força para permanecer nesse repouso e, por conseguinte, para resistir a tudo quanto pudesse alterá-lo; igualmente, quando se move tem força para continuar o seu movimento, isto é, para se mover com a mesma velocidade e para o mesmo lado. Mas a quantidade desta força deve ser avaliada tendo em conta o tamanho do corpo a que pertence, a superfície resultante da separação dos corpos, a velocidade do movimento e as maneiras como os diversos corpos se interceptam ${ }^{15}$.

Os cartesianos se encarregaram posteriormente de esclarecer, baseados nas palavras de Descartes, que a força de um corpo em movimento é o produto de sua massa por sua velocidade, ou, $\mathrm{F}=m v$. Todavia, para compreender esta ou quaisquer outras considerações cartesianas sobre o

\footnotetext{
14 Cf. LAUDAN, L. L. "The Vis viva controversy: A Post-Mortem". In: The History of Science Society, Chicago, vol. 59, n. 2, pp. 130-143, jun./ago. 1968, pp. 130-140.

15 DESCARTES, René. Princípios da Filosofia. Lisboa: Edições 70, 1997, p. 80.
} 
movimento, é preciso considerar que a física de Descartes está ancorada em sua metafísica, que tem, como um de seus princípios básicos, a existência, em todo o universo, de apenas dois tipos de substâncias, essencialmente distintas, a saber, a res cogitans e a res extensa, sendo a essência da primeira o pensamento e, da segunda, a extensão. Ao reduzir a matéria exclusivamente à sua extensão, Descartes elimina os traços qualitativos da física herdados da obra aristotélica, permitindo à mesma, agora, lançar mão da geometria para explicar os fenômenos ${ }^{16}$. É coerente, por conseguinte, que Descartes não possa considerar a matéria senão como um princípio passivo e inerte, não admitindo nela qualquer sorte de força interna, mas apenas forças mecânicas ${ }^{17}$. Não é de se espantar que um dos grandes problemas, para esta física, seja explicar a mudança de direção de um corpo em movimento.

Desse modo, tomando a concepção dualista de substância e a constatação do movimento dos corpos materiais, Descartes deve explicar não apenas como o movimento acontece, mas porque propriamente há o movimento. Sua resposta é: Deus é a causa geral de todo o movimento do mundo. No momento da criação, Ele deu origem tanto à matéria quanto ao movimento e

\footnotetext{
16 "Não acrescento aqui mais nada a respeito das figuras, nem sobre o modo como acontecem diversidades incontáveis nos movimentos devido às suas infinitas variedades, tanto mais que estas coisas podem ser compreendidas quando se falar delas, pressupondo-se que aqueles que leem os meus escritos conhecem os elementos da Geometria, ou que pelo menos o seu espírito seja dado à compreensão das demonstrações da Matemática. Confesso francamente que nas coisas corporais a única matéria que conheço é aquela que pode ser dividida, representada e movimentada de todas as maneiras possíveis, isto é, aquela matéria a que os geômetras chamam quantidade e que é objeto das suas demonstrações; nesta matéria só considero as suas divisões, figuras e movimentos" (DESCARTES, René. Princípios da Filosofia. Lisboa: Edições 70, 1997, p. 90-91).

${ }_{17}$ "Muito embora Descartes, particularmente em seus primeiros escritos, refira-se a forças de atração exercidas pela terra sobre um objeto em queda e explique o movimento acelerado de um tal objeto por uma ação cumulativa da força, ele, eventualmente, concebe a força como uma aparência fictícia. Sua dicotomia absoluta da existência em matéria pura e espírito puro pareceu a ele incompatível com a pressuposição de força na matéria ou exercida pela matéria, uma vez que a força, em sua visão, é ainda de algum modo uma noção física. A matéria tem de ser desvestida de todos os constitutivos espirituais, de todas as formas ou tendências. Apenas a extensão e o movimento eterno são suas características" (JAMMER, Max. The Concepts of Force. Harper Torchbook, 1962, p. 103).
} 
ao repouso $0^{18}$. Desde então, o somatório da quantidade de movimento presente no mundo não se altera. O movimento já não pode ser criado nem destruído. O movimento não é perdido por um corpo sem ser, na verdade, transferido a outro. O princípio da constância da somatória da quantidade de movimento se apoia na perfeição de Deus que é imutável e age de maneira regular - o que, de resto, serve de fundamento também para as leis da natureza. ${ }^{19}$. É esta quantidade geral de movimento que é calculada por $\mathrm{F}=m v$. A fórmula, por conseguinte, mais do que uma questão mecânica específica, expressa um princípio fundamental da metafísica e da física de Descartes.

De outra parte, Leibniz, em março de 1686, publica, na Acta Eruditorum, alguns pensamentos a respeito da mecânica cartesiana ${ }^{20}$. Evidentemente, o horizonte metafísico de Leibniz, no qual se insere sua física, é muito diferente da visão de Descartes. De um lado, ele estava consciente dos grandes problemas legados à filosofia pela concepção dualista de substância formulada por Descartes. De outro, tendo em mente algumas evidências da própria matemática e da ciência da natureza ${ }^{21}$, já não podia admitir que a matéria consistisse tão somente em extensão. Antes de mais nada, para

\footnotetext{
18 "Quanto à primeira [causa do movimento], parece-me evidente que só pode ser Deus, cuja onipotência deu origem à matéria com o seu movimento e o repouso das suas partes, conservando agora no universo, pelo seu concurso ordinário, tanto movimento e repouso como quando o criou. Com efeito, dado que o movimento não é mais do que um modo na matéria que se move, tem por isso uma certa quantidade que nunca aumenta nem diminui" (DESCARTES, René. Princípios da Filosofia. Lisboa: Edições 70, 1997, p. 75).

19 DESCARTES, René. Princípios da Filosofia. Lisboa: Edições 70, 1997, p. 75-76.

20 Brevis demonstration erroris memorabilis Cartesii et aliorum circa legem naturalem, secundum quam volunt a Deo eandem semper quantitatem motus conservari, qua et in re mechanica abuntur. Cf. LEIBNIZ, Gottfried Wilhelm. "A Brief Demonstration of a Notable Error of Descartes and Others Concerning a Natural Law". In: LOEMKER, Leroy E. Gottfried Wilhelm Leibniz Philosophical Papers and Letters. Dordrecht: Kluwer Academic Publishers, 1989, p. $296 \mathrm{ss}$.

${ }_{21}$ Na compreensão leibniziana de força, por exemplo, já se delineia, claramente, o problema, pois ela se apresenta a ele não como um princípio mecânico e exterior ao corpo, mas como algo quase vital da constituição do próprio corpo: "Ora. esta força é algo diferente do tamanho, da figura e do movimento, e por aí pode-se julgar não consistir apenas na extensão e suas modificações tudo o que se concebe no corpo, como se persuadem os nossos modernos. Assim, somos obrigados a restaurar alguns entes ou formas por eles banidos" (LEIBNIZ, Gottfried Wilhelm. "Discurso de metafísica". In: BARAÚNA, Luiz João; CHAUÍ, Marilena; MARICONDA, Pablo Rubén; MATTOS, Carlos Lopes de (trad.). Os Pensadores: Newton-Leibniz. São Paulo: Editora Abril: 1983, p. 143).
} 
dar conta do dinamismo da natureza, a metafísica, na sua perspectiva, deveria lançar mão de conceitos que já havia enterrado, como a forma substancial e a causalidade final. A bem da verdade, a metafísica tradicional, tendo sido vítima de uma crise mais ou menos aberta, acabou sendo substituída por uma filosofia primeira "declinada na primeira pessoa do presente do indicativo" ${ }^{22}$ e perdeu de vista seu caráter de ciência universal do ser enquanto ser. Assim, a metafísica de Leibniz bem pode ser descrita como uma tentativa de conciliação entre o sonho dos antigos de uma ciência geral da substância e o projeto moderno de uma mathesis universalis.

Embora dotado de grande precisão e rigor conceitual, Leibniz não apresentou seu pensamento numa forma sistemática. De qualquer modo, na Monadologia, obra da sua maturidade (escrita em 1714 e publicada apenas no século XIX), é possível contemplar alguns dos principais elementos de sua metafísica. Todas as coisas são compostas de substâncias simples, chamadas "mônadas", verdadeiros átomos ou elementos da natureza, nos quais não há extensão, figura ou divisibilidade. As mônadas não podem começar a existir nem perecer naturalmente, mas apenas por criação e aniquilamento. Não há interação íntima entre as mônadas; estas "não têm janelas"; as mudanças naturais procedem de um princípio interno a elas. Não obstante, são dotadas de qualidades próprias, pois, de outra forma, não seria possível explicar a diferença entre as coisas (princípio dos indiscerníveis). As mônadas são dotadas de percepção, capacidade de se representar o múltiplo na unidade. O que difere, por exemplo, a alma humana das coisas materiais é tão somente o fato de que esta é formada por mônadas de uma percepção mais distinta e acompanhada de memória. Mas vê-se, igualmente, percepções apuradas, por exemplo, entre os animais (memória e imaginação). Próprio dos seres humanos, porém, é o conhecimento das verdades necessárias e eternas, que os eleva ao co-

22 Cf. GRONDIN, Jean. Introducción a la metafísica. Espanha: Herder, 2006, p. 206 ss. O autor também oferece uma boa síntese da metafísica de Leibniz, para além dos elementos que estritamente interessam aqui. 
nhecimento de si e de Deus e lhes permite chegar à razão e às ciências. 0 conhecimento destas verdades e sua abstração levam aos atos de reflexão: o pensamento voltado para o $\mathrm{Eu}$, que permite reconhecer o que está e o que não está em si, e fornece os objetos principais dos raciocínios, que, por sua vez, fundam-se no conhecido princípio de contradição e também no princípio da razão suficiente ${ }^{23}$. Já que todas as coisas devem ter uma razão, sua razão última encontra-se numa substância necessária, que é Deus perfeito, em contraposição à imperfeição das criaturas. Ele é necessário, pois sua essência implica necessariamente a existência. Esse atributo the é também único: as demais mônadas passam da essência à existência por meio da atividade criadora de Deus ${ }^{24}$. Só Ele existe necessariamente; as demais coisas são contingentes. Nele há potência (origem de tudo), conhecimento (ideias particulares) e vontade (que provoca as mudanças ou produções). À semelhança disso, as mônadas criadas possuem fundamentalmente faculdade perceptiva e apetitiva ${ }^{25}$. Entre elas só é possível a interação física exterior. A modificação interior só pode acontecer com a intervenção de Deus, segundo a harmonia que Ele próprio estabeleceu de antemão. Graças a essa harmonia, as relações de uma substância simples expressam todas as demais, de modo que cada uma delas é "um espelho

\footnotetext{
23 "[...] pelo qual entendemos não poder algum fato ser tomado como verdadeiro ou existente, nem algum enunciado ser considerado verídico, sem que haja uma razão suficiente para ser assim e não de outro modo, embora frequentemente tais razões não possam ser conhecidas por nós" (LEIBNIZ, Gottfried Wilhelm. "Monadologia”. In: BARAÚNA, Luiz João; CHAUÍ, Marilena; MARICONDA, Pablo Rubén; MATTOS, Carlos Lopes de (trad.). Os Pensadores: Newton-Leibniz. São Paulo: Editora Abril: 1983, p. 108).

24 "Assim, só Deus é unidade primitiva, ou a substância simples originária de que todas as Mônadas criadas ou derivadas são produções e nascem de momento a momento, digamos assim, por Fulgurações contínuas da Divindade, restringidas pela receptividade da criatura, para a qual é essencial ser limitada" (LEIBNIZ, Gottfried Wilhelm. "Monadologia". In: BARAÚNA, Luiz João; CHAUÍ, Marilena; MARICONDA, Pablo Rubén; MATTOS, Carlos Lopes de (trad.). Os Pensadores: Newton-Leibniz. São Paulo: Editora Abril: 1983, p. 110).

25 Cf. LEIBNIZ, Gottfried Wilhelm. "Monadologia”. In: BARAÚNA, Luiz João; CHAUÍ, Marilena; MARICONDA, Pablo Rubén; MATTOS, Carlos Lopes de (trad.). Os Pensadores: Newton-Leibniz. São Paulo: Editora Abril: 1983, pp. 105-111.
} 
vivo e perpétuo do universo"26 - este, à semelhança da substância simples, é um só, mas pode ser observado de infinitas perspectivas pelas mônadas individuais (perspectivismo). Sendo as mônadas espelhos vivos do universo, então cada porção de matéria possui também "movimento próprio" e nela há "a existência de um mundo de criaturas, de viventes, de animais, de Enteléquias e de almas"27. Ainda devido à harmonia preestabelecida por Deus, alma e corpo seguem suas próprias leis e se ajustam perfeitamente. Não se pode negar, à diferença de Descartes, que a alma não possa intervir na direção dos $\operatorname{corpos}^{28}$. Há perfeita harmonia, ainda, entre o reino das causas eficientes e o reino das causas finais e, também, entre o reino físico da natureza e o reino moral da graça.

Tendo em mente esse panorama, é possível voltar a Brevis demonstratio de Leibniz. Numa questão tão particular, como esta da medida da força de um corpo em movimento, encontra mais uma comprovação de que não é possível considerar a matéria apenas como pura extensão e ignorar que seja dotada de uma atividade interna ou de uma força incapaz de ser explicada exterior e mecanicamente. Com efeito, Leibniz parece concordar com Descartes ao afirmar que a quantidade de força ${ }^{29}$ (chamada por ele, especificamente, de "força motriz") deve ser conservada na natureza. Contudo, está convencido de

${ }^{26}$ LEIBNIZ, Gottfried Wilhelm. "Monadologia". In: BARAÚNA, Luiz João; CHAUÍ, Marilena; MARICONDA, Pablo Rubén; MATTOS, Carlos Lopes de (trad.). Os Pensadores: Newton-Leibniz. São Paulo: Editora Abril: 1983, p. 110.

27 LEIBNIZ, Gottfried Wilhelm. "Monadologia". In: BARAÚNA, Luiz João; CHAUÍ, Marilena; MARICONDA, Pablo Rubén; MATTOS, Carlos Lopes de (trad.). Os Pensadores: Newton-Leibniz. São Paulo: Editora Abril: 1983, p. 112.

28 “Descartes reconheceu a impossibilidade de as almas transmitirem força aos corpos, porque há sempre a mesma quantidade força na matéria. Acredito, no entanto, na possibilidade de a alma mudar a direção dos corpos. A razão disso foi desconhecer-se no seu tempo a lei da natureza que garante também a conservação da mesma direção total na matéria. Se a conhecesse, cairia no meu sistema da Harmonia preestabelecida" (LEIBNIZ, Gottfried Wilhelm. "Monadologia". In: BARAÚNA, Luiz João; CHAUÍ, Marilena; MARICONDA, Pablo Rubén; MATTOS, Carlos Lopes de (trad.). Os Pensadores: Newton-Leibniz. São Paulo: Editora Abril: 1983, p. 113). No problema das possíveis relações entre alma e corpo, esta é a teoria da harmonia preestabelecida. Havia também, como possibilidades, a teoria do ocasionalismo e a teoria do influxo físico. Esta última admitida por Kant nos Pensamentos, como se verá.

29 Uma das maiores confusões terminológicas da disputa é, justamente, entre quantidade de movimento e força, propriamente. 
que este último se equivocou ao ter, supostamente, identificado força motriz com quantidade de movimento - e é este equívoco que quer demonstrar:

Ora, uma vez que é razoável que a mesma soma de força motriz deva ser conservada na natureza e não diminuída - uma vez que nós nunca vemos a força ser perdida por um corpo sem ser transferida a outro - ou aumentada, uma máquina de movimento perpétuo jamais poderia ser bem-sucedida porque nenhuma máquina, nem mesmo o mundo como um todo, pode aumentar sua força sem um novo impulso a partir do exterior. Isso levou Descartes, que considerou força motriz e quantidade de movimento como equivalentes, a afirmar que Deus conserva a mesma quantidade de movimento no mundo ${ }^{30}$.

Para demonstração do suposto equívoco de Descartes, Leibniz elenca as seguintes proposições ${ }^{31}$ :

P (1): Um corpo que cai de uma certa altura adquire a mesma força que é necessária para levá-lo à altura original, se este mantém sua direção e não sofre interferência de um elemento exterior.

P (2): A mesma força necessária para levantar um corpo (A) de uma libra até a altura $(C D)$ de 4 jardas é necessária para levantar outro corpo (B) de 4 libras a uma altura (EF) de uma jarda ${ }^{32}$.

C (1): Logo, o corpo $A$, ao cair da altura $C D$ deve adquirir precisamente a mesma quantidade de força que o corpo $B$ ao cair da altura $E F$.

$\mathbf{P}(3)$ : Porém, Galileu provou que a velocidade ( $v$ ) adquirida por um corpo ao cair da altura $C D$ é duas vezes a velocidade adquirida por outro que cai da altura $E F$.

30 LEIBNIZ, Gottfried Wilhelm. "A Brief Demonstration of a Notable Error of Descartes and Others Concerning a Natural Law". In: LOEMKER, Leroy E. Gottfried Wilhelm Leibniz Philosophical Papers and Letters. Dordrecht: Kluwer Academic Publishers, 1989, p. 296.

${ }_{31}$ Cf. LEIBNIZ, Gottfried Wilhelm. "A Brief Demonstration of a Notable Error of Descartes and Others Concerning a Natural Law". In: LOEMKER, Leroy E. Gottfried Wilhelm Leibniz Philosophical Papers and Letters. Dordrecht: Kluwer Academic Publishers, 1989, p. 296-298.

${ }^{32}$ Cartesianos e outros matemáticos concordariam com esta proposição. 
C (2): Sendo $v_{A}=2$ e $v_{B}=1$, temos: $F=m v \partial F_{A}=1 \times 2=2 \partial F_{B}=4 \times 1=4$. Vê-se claramente que a força do corpo $B$ é duas vezes a força do corpo $A$. Há, portanto, uma grande diferença entre força motriz (F) e quantidade de movimento $(m v)$ e uma não pode ser calculada pela outra.

Leibniz celebra a simplicidade de sua prova. Dadas, não obstante, suas discussões com cartesianos como Abbé Catelan em 1686 e Denis Papin em 1691, dentre outros, assiste-se depois a uma apresentação ainda mais clara na primeira parte de Specimen dynamicum, em 1695, onde introduzirá publicamente pela primeira vez ${ }^{33}$ o termo "força viva" e, mais claramente, sua mensuração como produto da massa do corpo em movimento pelo quadrado de sua velocidade.

O filósofo inicia a argumentação reiterando sua concepção dinâmica da matéria:

Sugerimos em outro lugar que há algo além da extensão nas coisas corpóreas; de fato, que há algo anterior à extensão, a saber, uma força natural implantada pelo Autor da natureza em todo lugar - uma força que não consiste apenas numa simples faculdade tal como aquela com a qual os escolásticos parecem ter se contentado, mas que é provida, além disso, de um empenho ou esforço [conatus seu nisus], que tem seu pleno efeito, a menos quando impedido por uma força contrária. Este nisus às vezes aparece aos sentidos e deve ser compreendido, na minha opinião, em bases racionais, como presente em todo lugar na matéria, mesmo onde não apareça aos sentidos. Mas se não podemos atribui-la a Deus como que por milagre, é certamente necessário que esta força seja produzida por ele nos corpos em si mesmos. De fato, ela deve constituir a natureza mais íntima do corpo, uma vez que é característica da substância agir, e extensão significa somente a continuação ou a difusão de uma

33 Cf. ILTIS, Carolyn. "Leibniz and The Vis Viva Controversy". In: The History of Science Society, Chicago, vol. 62, n. 1, pp. 21-35, jan./mar. 1971, p. 27 ss. 
pressuposta substância que age e resiste. Quão longe está a extensão de abranger em si mesma a substância! ${ }^{34}$

Ato contínuo, Leibniz classifica a força em ativa e passiva. A primeira é responsável pelo movimento e é interna aos corpos. A segunda é, na verdade, a resistência dos corpos ao movimento. A força ativa se subdivide em força primitiva e força derivativa. A força primitiva é a primeira enteléquia, a alma ou forma substancial. A força derivativa é resultado da limitação da força primitiva por meio do conflito dos corpos uns com os outros. A força primitiva, por sua natureza, pertente às causas gerais e, por isso, não basta para explicar o fenômeno. Ademais, esta forma não pode ser utilizada para explicar as causas específicas das coisas sensíveis. As concepções físico-mecânica e teológico-teleológica do mundo não são mutuamente excludentes, mas não se deve fazer uso de princípios espirituais para explicar fenômenos propriamente físicos, que se limitam ao âmbito dos princípios da filosofia corpuscular - as ciências físicas com seu método matemático ${ }^{35}$.

Leibniz leva adiante as definições. A velocidade somada à direção é o conatus (hoje, velocidade vetorial). A quantidade de movimento dos cartesianos, produto da massa pela velocidade, é designada impetus. Todavia, a distinção conceitual que mais importa à controvérsia, no Specimen dynamicum, é justamente entre "forças mortas" e "forças vivas". As forças mortas são descritas como uma "solicitação ao movimento", algo equivalente ao que hoje é denominado energia potencial. A força, combinada com o movimento atual, é chamada força viva (vis viva). Ela equivale, hoje, à energia cinética ${ }^{36}$. A força viva é o produto da massa de um corpo e o quadrado da sua velocidade - ou $\mathrm{F}=m v^{2}$.

\footnotetext{
34 LEIBNIZ, Gottfried Wilhelm. "Specimen dyamicum". In: LOEMKER, Leroy E. Gottfried Wilhelm Leibniz Philosophical Papers and Letters. Dordrecht: Kluwer Academic Publishers, 1989, p. 435.

35 Cf. LEIBNIZ, Gottfried Wilhelm. "Specimen dyamicum". In: LOEMKER, Leroy E. Gottfried Wilhelm Leibniz Philosophical Papers and Letters. Dordrecht: Kluwer Academic Publishers, 1989, p. 436. Cf. também JAMMER, Max. The Concepts of Force. Harper Torchbook, 1962, p. 158.

${ }_{36}$ Cf. LEIBNIZ, Gottfried Wilhelm. "Specimen dyamicum". In: LOEMKER, Leroy E. Gottfried Wilhelm Leibniz Philosophical Papers and Letters. Dordrecht: Kluwer Academic Publishers, 1989, p. 436-443.
} 
Ao se contemplar hoje a controvérsia da vis viva, é possível entrever que, efetivamente, tratava-se, em boa parte, de uma confusão conceitual, no que d'Alembert tem plena razão. Descartes chegou ao que hoje se chama de momentum ou quantidade de movimento $(\mathrm{mv})$ e Leibniz esteve próximo da fórmula do cálculo da energia cinética (na verdade, $E=1 / 2 m v^{2}$ ). Estes dois conceitos distintos foram discutidos como um único conceito, o conceito de "força" - de resto, bem diferente da ideia newtoniana de força ${ }^{37}$.

\section{A POSIÇÃO DE KANT NO DEBATE}

No início do terceiro capítulo de Pensamentos, Kant deixa claro que o que oferece à polêmica é uma solução de compromisso, dando razão a cartesianos e leibnizianos, mas em âmbitos distintos. A medida de força dos primeiros se aplica aos corpos matemáticos e, a dos segundos, aos corpos naturais.

Por conseguinte, demonstramos, minuciosamente, que a estimação das forças segundo o quadrado mostra-se falsa na matemática e que esta não permite nenhuma outra medida de força a não ser a antiga ou cartesiana. Entretanto, em diferentes passagens do capítulo anterior, levamos o leitor a esperar que se possa, não obstante, introduzir a estimação das forças segundo o quadrado na natureza, e agora é a hora de cumprir nossa promessa. Essa empresa audaciosa deixará perplexa a maioria de meus leitores, pois parece seguir-se disso que a matemática não é imune ao engano, no que se refere a apelar ao seu veredito. Contudo, a coisa não é assim.

37 cf. ILTIS, Carolyn. "Leibniz and The Vis Viva Controversy". In: The History of Science Society, Chicago, vol. 62, n. 1, pp. 21-35, jan./mar. 1971, p. 21. Ernan McMullin afirma que a posição de Newton é intermediária em relação a Descartes e Leibniz: por um lado, vê a ontologia cartesiana como insuficiente em relação aos movimentos, com exceção dos inerciais, e introduz a força como um elemento ontológico; por outro, prefere como força primária não a vis viva de Leibniz, mas a vis impressa (correspondente à "força morta" de Leibniz) e exclui, com o princípio de inércia, a força viva, porque o movimento uniforme não a requer nem é constituído por ela. Cf. McMULLIN, Ernan. Newton on Matter and Activity. Notre Dame, London: University of Notre Dame Press, 1978, p. 32. 
Se a matemática pronunciasse sua lei sobre todos os corpos em seu conjunto, então os corpos naturais seriam compreendidos nisso, e seria vão esperar uma exceção (Ak I, 139).

O trecho supracitado apresenta com clareza a estrutura do argumento e suas etapas dentro do quadro do tratado. Com efeito, a obra se estrutura em três partes, além de um prefácio (I-XIII). Na primeira, "Da força dos corpos em geral” (§§1-19), o filósofo fixa alguns conceitos metafísicos que considera necessários à discussão. Na segunda e maior parte, aludida no trecho supracitado, examina a doutrina dos partidários de Leibniz sobre as forças vivas, criticando seus argumentos matemáticos e dando preferência, neste âmbito, aos cartesianos ( $\$ \S 20-113)$. Na terceira, por fim, indica a nova estimação das forças vivas como a verdadeira medida das forças da natureza ( $\$ \S 114-163)$. Apresenta-se, a seguir, um breve panorama da obra, com ênfase no primeiro capítulo, pois este contém definições conceituais importantes para a compreensão da solução apresentada pelo filósofo.

Assim, no capítulo primeiro, intitulado "Da força dos corpos em geral" (Ak I, 17-31), Kant apresenta uma série de distinções que serão utilizadas na solução sustentada por ele. De início, concorda com Leibniz em afirmar que todos os corpos têm uma força essencial, anterior até mesmo à extensão (\$1), e que este, corretamente, chamou de "força ativa" (wirkende Kraft). Seus discípulos, porém, no desejo de definir esta força mais precisamente, preferiram chamá-la de "força motriz" (bewegende Kraft), expressão obscura, de tipo escolástico, e que pouco responde sobre a pergunta pela verdadeira causa do movimento (\$2). Ação e movimento não se identificam, já que o corpo que se move mais facilmente é justamente o que menos resistência (ou ação) manifesta (\$3). A caracterização da força essencial dos corpos como ativa é mais adequada e explica mais facilmente também a causa do movimento.

As maiores dificuldades para a consideração da força essencial dos corpos como força motriz (e não como força ativa) residem, especialmente, na doutrina da relação entre alma e corpo. Se a força dos corpos é motriz, não se pode explicar nem como a matéria é capaz de gerar representações 
e ideias na alma humana ( $(5)$, nem como a alma pode agir sobre o corpo (§6), dificuldade que é eliminada ao se retornar à consideração original de Leibniz: "Ambas as dificuldades, porém, desaparecem, e o influxo físico recebe não pouca luz, quando se coloca a força da matéria não na conta do movimento, mas em seus efeitos em outras substâncias, os quais não devem ser ulteriormente especificados" ( $A k I, 20)$.

Esta concepção da força dos corpos como força ativa dá azo para digressões sobre a existência de coisas sem ocupar nenhum lugar no mundo ( $\$ 7$ ), sobre a possibilidade da existência de outros mundos ( $\S 8 \mathrm{e}$ $\S 11)$, sobre a impossibilidade do espaço e da extensão sem a força ativa (§9) e as possíveis razões de sua tridimensionalidade (§10). Voltando ao argumento principal, após considerar que a força dos corpos se irradia em forma de movimento em todas as direções (§§12-14), Kant apresenta, ato contínuo, a distinção mais importante para a solução que depois vai apresentar, a saber, aquela entre dois tipos de movimento: o primeiro tipo de movimento "tem a propriedade de manter-se a si mesmo no corpo ao qual ele foi comunicado e de continuar infinitamente, se nenhum obstáculo se opor a ele" (Ak I, 28); o segundo tipo é "um efeito permanente de uma força constantemente propulsora, em que nem mesmo uma resistência é necessária para destruí-lo, mas se baseia apenas na força exterior e mesmo desaparece rapidamente quando esta cessa de sustentá-lo" (Ak I, 28; §15). Este segundo tipo de movimento não se diferencia de "pressão morta" (§16). Já o primeiro tipo pressupõe outra força, a força viva, que deve ser medida pelo quadrado da velocidade e que é interna ao corpo. Pressões mortas são medidas meramente pela velocidade e são exteriores a ele (cf. Ak I, 30; $\S \S 17-18)$. O capítulo se fecha com algumas considerações sobre a metafísica, que, por vezes, ampara suas provas em preconceitos e ambiciona estender o conhecimento humano sem, no entanto, cuidar de sua solidez ( $\$ 19)$.

O segundo capítulo, intitulado "Exame dos teoremas do partido leibniziano a respeito das forças vivas" (Ak I, 32-138) constitui a maior parte da obra. Deixando de lado os argumentos metafísicos, Kant agora procura derrubar, por meio de demonstrações matemáticas, as provas que 
pareciam dar razão aos leibnizianos, mostrando-se favorável, neste âmbito, a Descartes, embora já anuncie que não pretende também abrir mão da tese das forças vivas, como o percurso argumentativo poderia sugerir:

\begin{abstract}
Mas eu ainda não renunciei por completo, por este motivo, às forças vivas. No terceiro capítulo deste tratado demonstrarei que há que se encontrar verdadeiramente na natureza forças cuja medida é o quadrado de sua velocidade; apenas com a restrição de que nunca serão descobertas da maneira com que se iniciou até aqui, ou seja, que elas estarão escondidas para sempre deste tipo de consideração (a saber, a matemática) e que nada a não ser uma investigação metafísica ou, por assim dizer, um tipo especial de experiência, poderá tornar as mesmas conhecidas a nós. Contestamos aqui, portanto, não a coisa mesma, mas simplesmente o modum cognoscendi (Ak I, 59-60).
\end{abstract}

Embora Kant dê esta garantia ao leitor, é difícil, para quem seguiu o curso natural da leitura, imaginar, neste ponto, como o filósofo "salvará" a estimação leibniziana, posto que derruba com argumentos matemáticos demonstrações mecânicas que pareciam favoráveis a esta, sejam relativas aos corpos em queda livre ( $\S \S 30-36)$, às colisões elásticas ( $\S \S 37-57)$ e inelásticas ( $\S \S 58-70)$, movimentos compostos ( $\S \S 71-78)$, oblíquos e circulares ( $\S \S 79-85)$; os últimos parágrafos lidam, ainda, com outros casos discutidos por Leibniz ( $\S 92-102)$, Wolff ( $\S \S 103-106)$, Musschenbroek (§§107-108), Jurin, Chastelet e Richter (§§109-113).

Finalmente, no terceiro capítulo, Kant apresenta a solução, já anunciada no início deste tópico: a estimação cartesiana valeria para os corpos matemáticos, enquanto a leibniziana, para os naturais. A explicação é a seguinte: o conceito matemático de corpo é estabelecido por meio de axiomas, os quais devem ser pressupostos nele. Estes excluem, em contrapartida, certas propriedades que necessariamente devem estar presentes nos corpos naturais. Assim, "o corpo matemático é uma coisa 
completamente diferente do corpo natural e, portanto, algo pode ser verdadeiro naquele sem, contudo, pertencer a este" (Ak I, 140). A matemática só pode admitir, num corpo, a força produzida por uma causa externa ao movimento, de modo que se encontrará a mesma quantidade de força no corpo em movimento do que na causa deste movimento. A única medida deste tipo de força é a cartesiana. Porém, o corpo natural tem outra constituição: "tem em si a capacidade de ampliar, em si e por si, a força que foi adquirida a partir do exterior por meio da causa de seu movimento, de modo que possa haver nele graus de força que não se originaram da causa exterior do movimento e também são maiores do que a mesma, e que não poderiam ser mensurados com a mesma medida com que a força cartesiana é mensurada, e também têm uma outra estimação" (Ak I, 140). Assim, "tem uma força viva um corpo que sustenta sua velocidade no movimento livre até o infinito, ou seja, uma força tal que tem como medida o quadrado da velocidade" (Ak I, 148).

Qual o valor científico da solução kantiana? Kant desconhece, a esta altura, o princípio da inércia ${ }^{38}$ que, no entanto, já estava estabelecido há algum tempo na mecânica. Ele não permitiria a supracitada distinção entre movimentos que se mantém no corpo e se prolongam infinitamente e movimentos que cessam quando cessa a força externa que os provoca, já que ambos estariam, na verdade, submetidos a este princípio. A classificação kantiana de movimentos produzidos por forças é errônea e aumenta a confusão conceitual ao invés de dirimi-la. Mariano Campo é taxativo ao dizer que "o grave desconhecimento da lei de inércia e a confusão sobre o conceito de aceleração denigre radicalmente o aspecto científico da tese sustentada por

\footnotetext{
${ }^{38}$ É certo que Kant já havia lido a Newton antes de escrever os Pensamentos. Mas parece ter aproveitado pouco da leitura: desconhece o princípio de inércia bem como o método e as formulações da filosofia natural newtoniana, excetuando-se a ideia da gravitação universal. A parte metafísica de Pensamentos segue a inspiração de Leibniz através de Wolff, e a parte matemática, a imagem que se fez da física cartesiana. Ademais, qualquer conhecimento que possa ter de Newton, nesse momento, pode muito bem ser obtido nos manuais ecléticos que ele próprio cita, como os Elementa physices, de Hamberger. Cf. CAÑEDO-ARGÜELLES, Juan Arana. "Kant y las tres físicas". In: SOCIEDAD CASTELLANO-LEONESA DE FILOSOFÍA. En Torno a la Filosofía Natural de Newton: Crisis de la Modernidad. Salamanca, 1991, pp. 58-59.
} 
este escrito juvenil" e que "longe de dominar a controvérsia, individuando seus equívocos e esclarecendo seus pontos fixos, o jovem graduando aumenta-lhe a obscuridade, trazendo confusão sobre conceitos fundamentais" ${ }^{\prime \prime}$. Uma vez que a solução apresentada se baseia fundamentalmente nesta distinção entre movimentos, já não há muito o que dela aproveitar.

Do ponto de vista filosófico, contudo, há diversos pontos de interesse na obra, sobretudo quando se tem em mente a história do desenvolvimento filosófico kantiano.

Em primeiro lugar, Kant trata com clareza do problema da relação entre alma e corpo, reforçando, com a distinção entre vis motrix e vis activa, a tese do influxo físico, preocupando-se, desde o início, em salvaguardar a liberdade do ser humano. O filósofo inicia seu trabalho afirmando que todo corpo em movimento tem uma força que se mostra, por exemplo, na superação de obstáculos. O problema é de onde advém esta força: apenas do exterior, como os sentidos parecem indicar? O corpo em repouso não possui força alguma? Leibniz parece ter acertado ao dizer que há uma força essencial inerente ao corpo, pertencente a ele antes mesmo da extensão, que ele chamou de vis activa. Seus discípulos, por desejo de maior precisão, acabaram por chamá-la de vis motrix - restringindo-a, assim, a uma força que nada faz senão produzir movimento e que é exercida apenas quando o movimento é atual, acreditando, assim, explicar sua causa, assemelhando-se à obscuridade dos escolásticos que explicavam o calor e o frio por uma vis calorifica e uma vis fragificiente. Não se pode reduzir a ação ao movimento: a força essencial dos corpos, em movimento ou repouso, é a força ativa e o movimento, que ela é plenamente capaz de explicar, é um fenômeno derivado (AK I, 17-19).

Esta sutil distinção permite esclarecer melhor a relação existente entre alma e corpo. $\mathrm{O}$ dualismo substancial cartesiano legara à posteridade $\mathrm{O}$ problema do relacionamento entre alma e corpo, já que se tratavam de

39 CAMPO, Mariano. "Osservazioni sul primo lavoro precritico di Kant. Sulla misura delle forze vive”. In: Rivista de filosofia neo-scolastica, Milano, v. 35, pp. 265-295, set./dez. 1943, p. 278. 
duas substâncias essencialmente diferentes. Havia, então, três modelos principais de explicação, a saber: o ocasionalismo - de resto, o primeiro a ser descartado, dado que tinha como pressuposto a ação divina para a explicação da harmonia entre alma e corpo, multiplicando os milagres ao infinito; a harmonia preestabelecida, de Leibniz e Wolff (embora, para Leibniz, ela não se restringisse à relação alma-corpo); e a teoria do influxo físico. A doutrina da harmonia preestabelecida imperou na escola wolffiana, sobretudo entre os anos de 1720 e 1724; mas, nos anos seguintes, foi duramente atacada por motivos religiosos e morais: da maneira como a doutrina se apresentava, embora, em boa medida, desfigurando a Leibniz, não era possível salvaguardar a liberdade pessoal. Se alma e corpo agem à base de leis, segundo a harmonia preestabelecida por Deus, é difícil afirmar a liberdade do ser humano. Descartes havia negado à mente a vis motrix, mas atribuiu-lhe, ao menos, a vis diretrix. Leibniz parecia negar ambas, de modo que não haveria diferença, mesmo se a alma não existisse, e o pecado seria imputado, em última instância, a Deus. Do ponto de vista do conhecimento, as representações também estariam comprometidas. Assim, a teoria do influxo físico, como teoria da ação real, pareceu a muitos da escola wolffiana (dentre eles, Martin Knutzen, o professor de Kant; Gottsched e Bucky) corresponder melhor ao espírito da filosofia de Leibniz, de modo que de 1732 a 1735 se estabeleceu dentro dela (A obra De commercio mentis cum corpore per influxum physicum, de Knutzen, é de 1735). A perspectiva leibniziana, por sua vez, causava grandes discussões não só no ambiente da universidade, mas também na cultura cotidiana ${ }^{40}$.

Kant está convencido de que a descrição da força dos corpos como vis activa ao invés de vis motrix, ou seja, como força de agir sobre outras substância(s), lança luz significativa sobre a polêmica: a pergunta se a alma é capaz de causar movimentos é transformada na pergunta se ela é capaz de agir fora de si sobre outras entidades e produzir mudanças

40 cf. CAMPO, Mariano. "Osservazioni sul primo lavoro precritico di Kant. Sulla misura delle forze vive". In: Rivista de filosofia neo-scolastica, Milano, v. 35, pp. 265-295, set./dez. 1943, p. 267-271. 
e a resposta desta última é afirmativa (Ak I, 20). Isso permite ao jovem filósofo reconhecer o mérito de seu professor, sem, contudo, deixar de conferir à sua resposta maior exatidão: "Nada mais impediu um certo agudo autor de obter plenamente o triunfo do influxo físico sobre a harmonia preestabelecida senão esta pequena confusão conceitual, da qual se saberá sair facilmente assim que se dirigir a atenção para isso" (Ak l, 21).

\section{Além disso, desde o início Kant se mostra interessado na relação entre} matemática, ciência e filosofia, que se tornará sempre mais o problema

crítico kantiano. Percebe que o problema se desdobra em duas direções: a mecânica, que considera o movimento, e a dinâmica, que se detém na força. Uma contém algo de fenomênico, outra, o real. Uma é o âmbito onde impera a matemática, a outra exige a metafísica. Está em jogo a relação problemática entre ciência moderna e filosofia. Delineia-se um projeto de dinâmica que se divide em dois polos: uma dinâmica científica e uma dinamologia metafísica. No título, Pensamentos sobre a verdadeira estimação das forças vivas, as "forças vivas" se revestem de um caráter eminentemente metafísico, enquanto a "estimação" se serve dos elementos físico-matemáticos ${ }^{41}$. As dúvidas acerca da solidez da metafísica acadêmica se tornam mais claras, ainda que de modo muito geral ${ }^{42}$. É evidente a tentativa de conciliação entre matemática e metafísica, que surpreende por não se alinhar ao modelo científico dominante ${ }^{43}$.

Destaca-se, por fim, a preocupação metodológica de Kant. Ao perceber um conflito fundamental na interpretação do fenômeno, nos princípios em que se fundamenta o exame da natureza, ele compreende que suas

\footnotetext{
${ }^{41}$ Cf. CAMPO, Mariano. "Osservazioni sul primo lavoro precritico di Kant. Sulla misura delle forze vive". In: Rivista de filosofia neo-scolastica, Milano, v. 35, pp. 265-295, set./dez. 1943, p. 283.

42 É significativo o juízo que Kant emite a respeito da metafísica no final do primeiro capítulo da obra: "Nossa metafísica, assim como muitas outras ciências, está, na realidade, somente no limiar de um conhecimento devidamente fundamentado; Deus sabe se alguém verá o mesmo ser ultrapassado. Não é difícil ver suas fraquezas em muito do que ela empreende. Encontra-se mui frequentemente o preconceito como a maior força de suas provas. Nada é mais culpado disso do que a inclinação dominante dos que procuram ampliar o conhecimento humano. Eles gostariam de possuir uma grande filosofia, contudo, seria desejável que esta fosse também sólida" (Ak I, 30-31). 43 cf. CASSIRER, Ernst. Kants Leben und Lehre. Berlin: Bruno Cassirer, 1921, p. 28.
} 
diversas áreas de jurisdição têm de ser avaliadas. Não está preocupado com a matéria da questão, mas "somente com o modum cognoscendi" (Ak I, 60). Embora não se possa considerar os Pensamentos como um tratado do método no sentido posterior da primeira Crítica ${ }^{44}$, é evidente o papel que essa obra desempenha: "Deve-se ter um método, através do qual se possa responder, através de uma consideração geral das proposições fundamentais em cada caso onde certa opinião foi construída e através da comparação da mesma com a consequência que dela é extraída, se também a natureza das premissas contém em si tudo o que é exigido em relação às doutrinas concluídas daí" (Ak I, 93). Como se vê, o "método" em questão ainda é o sintético (com juízos analíticos logicamente concatenados na cadeia de dedução) e não o método analítico de Newton (que faz uso da indução e dos juízos sintéticos ou de experiência). A tensão entre esses dois métodos será um dos problemas no programa filosófico de Kant, sobretudo com relação à metafísica. Na crítica da razão especulativa de 1781, ficará claro para ele que a metafísica não se constituiu como a ciência que pretendia ser não por uma razão metodológica, mas epistemológica, a saber, em função dos limites da própria razão, que só pode conhecer os fenômenos, embora possa pensar o suprassensível.

No entrecruzamento de questões metodológicas, científicas e metafísicas, Kant via a luz de uma única razão, ameaçada pela obscuridade da discussão e suas imprecisões conceituais. Seu desconhecimento dos principais avanços do conhecimento científico-matemático de seu tempo, longe de denegrir sua imagem, neste trabalho juvenil, mostra a agudeza de seu pensamento e a capacidade de lidar com questões tão diversificadas em vista de uma síntese ulterior, mesmo com tão poucos elementos em mãos. Nos Pensamentos, o caminho que o filósofo firmemente traçara para si já se mostrava auspicioso. Cabe levá-los a sério.

44 Conforme acredita Cassirer, ao destacar esta preocupação metodológica de Kant. Cf. CASSIRER, Ernst. Kants Leben und Lehre. Berlin: Bruno Cassirer, 1921, p. 28. 


\section{REFERÊNCIAS}

BOROWSKI, Ludwig Ernst. Darstellung des Lebens und Charakters Immanuel Kants. In: SCHWARZ, Hermann. Immanuel Kant: ein Lebensbild nach Darstellungen der Zeitgenossen. Halle: Hugo Peter, 1907.

CAMPO, Mariano. Osservazioni sul primo lavoro precritico di Kant. Sulla misura delle forze vive. Rivista di filosofia neo-scolastica, Milano, v. 35, p. 265-295, 1943.

CAÑEDO-ARGÜELLES, Juan Arana. Kant y las tres físicas. In: SOCIEDAD CASTELLANO-LEONESA DE FILOSOFÍA. En Torno a la Filosofía Natural de Newton: Crisis de la Modernidad. Salamanca, 1991. https://doi.org/10.15304/ ag.35.2.2726

CAÑEDO-ARGÜELLES, Juan Arana. Pensamientos sobre la verdadera estimación de las fuerzas vivas. Berna: Peter Lang, 1988.

CASSIRER, Ernst. Kants Leben und Lehre. Berlin: Bruno Cassirer, 1921.

DESCARTES, René. Princípios da Filosofia. Lisboa: Edições 70, 1997.

ERDMANN, Benno. Martin Knutzen und seine Zeit. Ein Beitrag zur Geschichte der Wolfischen Schule und insbesondere zur Entwicklungsgeschichte Kants. Leipzig: Verlag von Leopold Voss, 1876.

GRONDIN, Jean. Introducción a la metafísica. Espanha: Herder, 2006.

HANKINS, Thomas L. Eighteenth-Century Attempts to Resolve the Vis Viva Controversy. The History of Science Society, v. 56, n. 3, p. 281-297, 1965. https://doi.org/10.1086/349997

HÖFFE, Otfried. Imanuel Kant. São Paulo: Martins Fontes, 2005.

ILTIS, Carolyn. Leibniz and the Vis Viva Controversy. The History of Science Society, v. 62, n. 1, p. 21-35, 1971. https://doi.org/10.1086/350705

JAMMER, Max. The Concepts of Force. Harper Torchbook, 1962.

KANT, Immanuel. Thoughts on the true estimation of living forces and assessment of the demonstrations that Leibniz and other scholars of mechanics have made use of in this controversial subject, together with some prefatory considerations pertaining to the force of bodies in general (1746-1749). In: WATKINS, Eric (ed.). Natural Science -The Cambridge Edition of the Works of Immanuel Kant. Cambridge: Cambridge University Press, 2012.. https:// doi.org/10.1017/cbog781139014380.004 
KANT, Immanuel. Gedanken von der wahren Schätzung der lebendigen Kräfte und Beurteilung der Beweise, deren sich Herr von Leibniz und andere Mechaniker in dieser Streitsache bedient haben, nebst einigen vorhergehenden Betrachtungen, welche die Kraft der Körper überhaupt betreffen. In: Königlich Preußischen Akademie der Wissenschaften. Kants Gesammelte Schriften. Band 1. Berlin: Georg Reimer, 1910. https://doi.org/10.5962/bhl.title.37782 KUEHN, Manfred. Kant: A Biography. Cambridge: Cambridge University Press, 2002.

LAUDAN, L. L. The Vis Viva Controversy, a Post-Mortem. The History of Science Society, v. 59, n. 2, p. 130-143, 1968. https://doi.org/10.1086/350361 LEIBNIZ, Gottfried Wilhelm. A Brief Demonstration of a Notable Error of Descartes and Others Concerning a Natural Law. In: LOEMKER, Leroy E. Gottfried Wilhelm Leibniz Philosophical Papers and Letters. Dordrecht: Kluwer Academic Publishers, 1989. https://doi.org/10.2307/2216994

LEIBNIZ, Gottfried Wilhelm. Discurso de metafísica. In: BARAÚNA, Luiz João; CHAUÍ, Marilena; MARICONDA, Pablo Rubén; MATTOS, Carlos Lopes de (trad.). Os Pensadores: Newton-Leibniz. São Paulo: Editora Abril: 1983. https://doi.org/10.11606/issn.2318-8863.discurso.2015.112520

LEIBNIZ, Gottfried Wilhelm. “Monadologia”. In: BARAÚNA, Luiz João; CHAUÍ, Marilena; MARICONDA, Pablo Rubén; MATTOS, Carlos Lopes de (trad.). Os Pensadores: Newton-Leibniz. São Paulo: Editora Abril: 1983.

LEIBNIZ, Gottfried Wilhelm. "Specimen dyamicum". In: LOEMKER, Leroy E. Gottfried Wilhelm Leibniz Philosophical Papers and Letters. Dordrecht: Kluwer Academic Publishers, 1989. https://doi.org/10.2307/2216994

LESSING, G. E. Sämtliche Schriften. Band 13. Berlin: Voß'sche Buchhandlung, 1840. McMULLIN, Ernan. Newton on Matter and Activity. Notre Dame, London: University of Notre Dame Press, 1978. https://doi.org/10.1163/221058707x00152

\section{ENDEREÇO CORRESPONDÊNCIA:}

R. Monte Alegre, 984 - Perdizes, São Paulo - SP, 05014-901 